\title{
Pseudoangiomatous stromal hyperplasia tumor: a clinical, radiologic and pathologic study of 26 cases
}

\author{
Marco Ferreira ${ }^{1}$, Constance T Albarracin ${ }^{2}$ and Erika Resetkova ${ }^{2}$ \\ ${ }^{1}$ Serviço de Anatomia Patológica, Instituto Português de Oncologia de Lisboa Francisco Gentil, EPE, Lisboa, \\ Portugal and ${ }^{2}$ Department of Pathology, The University of Texas M. D. Anderson Cancer Center, Houston, \\ TX, USA
}

\begin{abstract}
Pseudoangiomatous stromal hyperplasia tumors are rare. In this retrospective study, we evaluated the clinical, radiologic, and pathologic features of pseudoangiomatous stromal hyperplasia tumors and compared histologic findings of pseudoangiomatous stromal hyperplasia tumors with clinical outcome. We identified 26 patients (mean age, 47 years) with pseudoangiomatous stromal hyperplasia tumors who had been diagnosed at our institution. Sixteen patients $(62 \%)$ were premenopausal, and $13(50 \%)$ had a history of oral contraceptive or hormone replacement therapy use. Ten patients $(38 \%)$ presented with a palpable mass; in the other patients, the tumors were detected by mammography (where it usually appeared as a hyperdense mass with irregular margins) or sonography (where it usually appeared as a hypoechoic mass). Lesions were a mean of $4.2 \mathrm{~cm}$ at the largest dimension (range, $0.8-11 \mathrm{~cm}$ ). Histologically, pseudoangiomatous stromal hyperplasia was classified as simple in 18 patients (69\%) and fascicular/proliferative in eight patients $(31 \%)$. In one patient $(4 \%)$, an invasive ductal carcinoma was present within the pseudoangiomatous stromal hyperplasia tumor. We found associated benign epithelial lesions in eight patients $(31 \%)$ and/or gynecomastia-like changes in 17 patients $(65 \%)$. The presence of gynecomastia-like changes was significantly associated with intralobular location of pseudoangiomatous stromal hyperplasia $(P=0.00085$, by Fisher's exact test). Follow-up data were available for 15 patients (mean \pm s.d., $\leq \mathbf{2 7} \pm 17$ months). No additional pathology or substantial changes in existing lesions were found on imaging. All pseudoangiomatous stromal hyperplasia tumors diagnosed by core needle biopsy but not subsequently excised remained clinically and radiologically stable; therefore, offering the option of close clinical surveillance instead of surgery in patients with pseudoangiomatous stromal hyperplasia tumors diagnosed by core needle biopsy in selected patients.
\end{abstract}

Modern Pathology (2008) 21, 201-207; doi:10.1038/modpathol.3801003; published online 14 December 2007

Keywords: pseudoangiomatous stromal hyperplasia; gynecomastia-like changes; core needle biopsy

Pseudoangiomatous stromal hyperplasia is a benign proliferation of breast stromal cells. The condition was first described in 1986 by Vuitch et $a l,{ }^{1}$ who identified it in nine patients with nodular mass lesions that morphologically simulated vascular proliferative lesions.

Pseudoangiomatous stromal hyperplasia is a relatively common incidental finding in breast tissue specimens from men and women, mostly appearing as scattered foci in association with benign breast

Correspondence: Dr E Resetkova, MD, PhD, Department of Pathology, Unit 85, The University of Texas M. D. Anderson Cancer Center, 1515 Holcombe Boulevard, Houston, TX 77030, USA.

E-mail: eresetko@mdanderson.org

Presented at the 21st European Congress of Pathology, Istanbul, Turkey, September 8-13, 2007.

Received 06 September 2007; revised 24 October 2007; accepted 31 October 2007; published online 14 December 2007 lesions. ${ }^{2-5}$ However, palpable masses and radiologically detected lesions consisting predominantly of pseudoangiomatous stromal hyperplasia cells are rare; the largest series reported in the medical literature includes 40 cases. ${ }^{6}$ The imaging findings of pseudoangiomatous stromal hyperplasia tumors have been reported only in small case series. $^{7-10}$

Because of the rarity of pseudoangiomatous stromal hyperplasia tumors and uncertainty about their clinical behavior, surgical excision has been the recommended treatment. ${ }^{1,3,6}$ Recently, most cases are initially diagnosed by image-guided core needle biopsy, which allows the option of close clinical and radiologic surveillance instead of surgical excision. No studies have yet evaluated the long-term clinical outcome of patients with pseudoangiomatous stromal hyperplasia tumors who undergo surveillance instead of surgical excision. 
The aim of this study was to review the clinical, radiologic, and histologic features of pseudoangiomatous stromal hyperplasia tumors and to compare the histologic findings in these tumors with the clinical outcome. We also identified what is, to our knowledge, the first case of invasive ductal carcinoma localized to a pseudoangiomatous stromal hyperplasia tumor.

\section{Patients and methods}

In this retrospective study, after approval by the institutional review board of The University of Texas M. D. Anderson Cancer Center, we searched the Department of Pathology database for all patients who had palpable or radiologically detected pseudoangiomatous stromal hyperplasia tumors from 1999 to 2007. Patients' clinical records were reviewed for demographic characteristics (age, sex, menopausal status, and use of birth control or hormone replacement therapy), relevant clinical histories, clinical findings, mammography and sonography findings, and clinical outcomes.

Hematoxylin and eosin-stained sections of all pseudoangiomatous stromal hyperplasia tumors were reviewed and classified, as described elsewhere, ${ }^{3,6}$ as simple (open, slit-like anastomosing channels without erythrocytes, lined by a discontinuous layer of flat cells without atypia) or fascicular/ proliferative (cellular proliferation areas composed of bland spindle cells without atypia). We evaluated all pseudoangiomatous stromal hyperplasia tumors for cytologic atypia within stromal cells and noted the pseudoangiomatous stromal hyperplasia location (intralobular stroma, perilobular stroma, or both) and associated epithelial findings (eg, fibrocystic changes, ductal hyperplasia without atypia, adenosis, apocrine metaplasia, fibroadenomatoid changes, gynecomastia-like changes, epithelial atypia, or carcinoma). Gynecomastia-like changes were defined as epithelial ductal change/hyperplasia of predominantly flat and micropapillary types, composed of both epithelial and myoepithelial cell proliferation surrounded by dense fibrotic periductal stroma, frequent periductal edema and a mildto-moderate degree of periductal lymphocytic infiltrate. A lack of breast lobule formation is frequently noted in association with gynecomastialike changes.

Statistical analyses were performed using Fisher's exact test, and a $P$-value of $<0.05$ considered statistically significant.

\section{Results}

\section{Clinical and Radiologic Findings}

We found 136 patients with pathologic diagnosis of pseudoangiomatous stromal hyperplasia in the database; 26 of these patients had underlying palpable or radiologically detected tumors and were thus eligible for this study. All 26 patients were women aged 19-70 years (mean, 47 years; median, 50 years). Sixteen patients $(62 \%)$ were premenopausal, and nine (35\%) were postmenopausal; information was not available in one case. Thirteen patients $(50 \%)$ had used oral contraceptives, and six postmenopausal patients $(23 \%)$ had used hormone replacement therapy. One patient had used both. The mean durations of oral contraceptive and hormone replacement therapy use were 10 years (median, 9 years) and 13 years (median, 12 years), respectively.

Clinical history of prior or concurrent breast cancer was observed in two patients. One patient had been diagnosed with invasive medullary carcinoma of the contralateral breast 6 years before the study began; this had been treated by surgical excision, radiation therapy, and chemotherapy. We

Table 1 Mammographic and sonographic findings

\begin{tabular}{|c|c|c|}
\hline Finding & $\begin{array}{l}\text { Mammography } \\
\quad(\mathrm{n}=22)\end{array}$ & $\begin{array}{l}\text { Sonography } \\
\quad(\mathrm{n}=25)\end{array}$ \\
\hline \multicolumn{3}{|l|}{ Type of lesion } \\
\hline Mass & 18 & 20 \\
\hline Normal & 4 & 5 \\
\hline \multicolumn{3}{|l|}{ Circumscription $^{\mathrm{a}}$} \\
\hline $\begin{array}{l}\text { Oval, well- } \\
\text { circumscribed }\end{array}$ & 5 & 7 \\
\hline $\begin{array}{l}\text { Irregular, indistinct } \\
\text { margins }\end{array}$ & 10 & 7 \\
\hline Not provided & 3 & 6 \\
\hline \multicolumn{3}{|l|}{ Density $^{\mathrm{a}}$} \\
\hline Isodense & 1 & NA \\
\hline Hypodense & 1 & NA \\
\hline Hyperdense & 11 & NA \\
\hline $\begin{array}{l}\text { Hypodense with } \\
\text { hyperdense areas }\end{array}$ & 1 & NA \\
\hline Not provided & 4 & NA \\
\hline \multicolumn{3}{|l|}{ Echogenicity } \\
\hline Hypoechogenic & NA & 14 \\
\hline $\begin{array}{l}\text { Hypoechogenic with } \\
\text { hyperechogenic areas }\end{array}$ & NA & 2 \\
\hline Not provided & NA & 4 \\
\hline \multicolumn{3}{|c|}{ Color doppler vascularity ${ }^{\mathrm{a}}$} \\
\hline Hypervascular & NA & 2 \\
\hline $\begin{array}{l}\text { Mild peripheral } \\
\text { hypervascularity }\end{array}$ & NA & 2 \\
\hline Normal & NA & 16 \\
\hline \multicolumn{3}{|c|}{ Differential diagnosis based on imaging } \\
\hline Fibrocystic changes & 4 & 2 \\
\hline $\begin{array}{l}\text { Suspicious for } \\
\text { fibroadenoma, } \\
\text { phylloides tumor, or } \\
\text { hamartoma }\end{array}$ & 0 & 4 \\
\hline $\begin{array}{l}\text { Suspicious for } \\
\text { malignancy }\end{array}$ & 3 & 3 \\
\hline Not provided & 11 & 11 \\
\hline
\end{tabular}

${ }^{\mathrm{a}}$ Evaluated in patients with masses only, demonstrated by mammography or sonography. 
found an ipsilateral concomitant invasive ductal carcinoma in one other patient; carcinoma was a solid irregular hypoechoic mass that measured $1.4 \mathrm{~cm}$ at its largest dimension and was $2.0 \mathrm{~cm}$ away from the pseudoangiomatous stromal hyperplasia tumor; the pseudoangiomatous stromal hyperplasia tumor had been detected during imaging of a mass and was suspected of being a satellite cancer nodule. Moreover, in one patient, invasive ductal carcinoma was localized within pseudoangiomatous hyperplasia tumor itself (see the case report on this patient below).

In two additional patients, pseudoangiomatous stromal hyperplasia tumors were found in the axillary tail of breast; the tumors were palpable and simulated lymphadenopathy, measuring 1.5 and $6.0 \mathrm{~cm}$.

Ten patients $(38 \%)$ had a history of a palpable lesion. In 12 patients (46\%), the lesion had been detected radiologically, and no information on lesion palpability was available for four patients.

The radiologic findings are shown in Table 1. Twenty-one patients (81\%) had undergone both mammography and sonography. Masses had been identified by mammography in 18 patients (69\%), sonography in 20 patients $(77 \%)$, and both modalities in 12 patients (46\%). As measured by sonography, lesions were $0.8-11.0 \mathrm{~cm}$ at the largest dimension (mean \pm s.d., $4.2 \pm 4.3 \mathrm{~cm}$ ).

\section{Histologic Findings}

Masses had been diagnosed as pseudoangiomatous stromal hyperplasia tumors by ultrasound-guided core needle biopsy in 14 cases (54\%), stereotactic core needle biopsy in seven cases $(27 \%)$, and initial surgical excision in five cases $(19 \%)$. The histologic
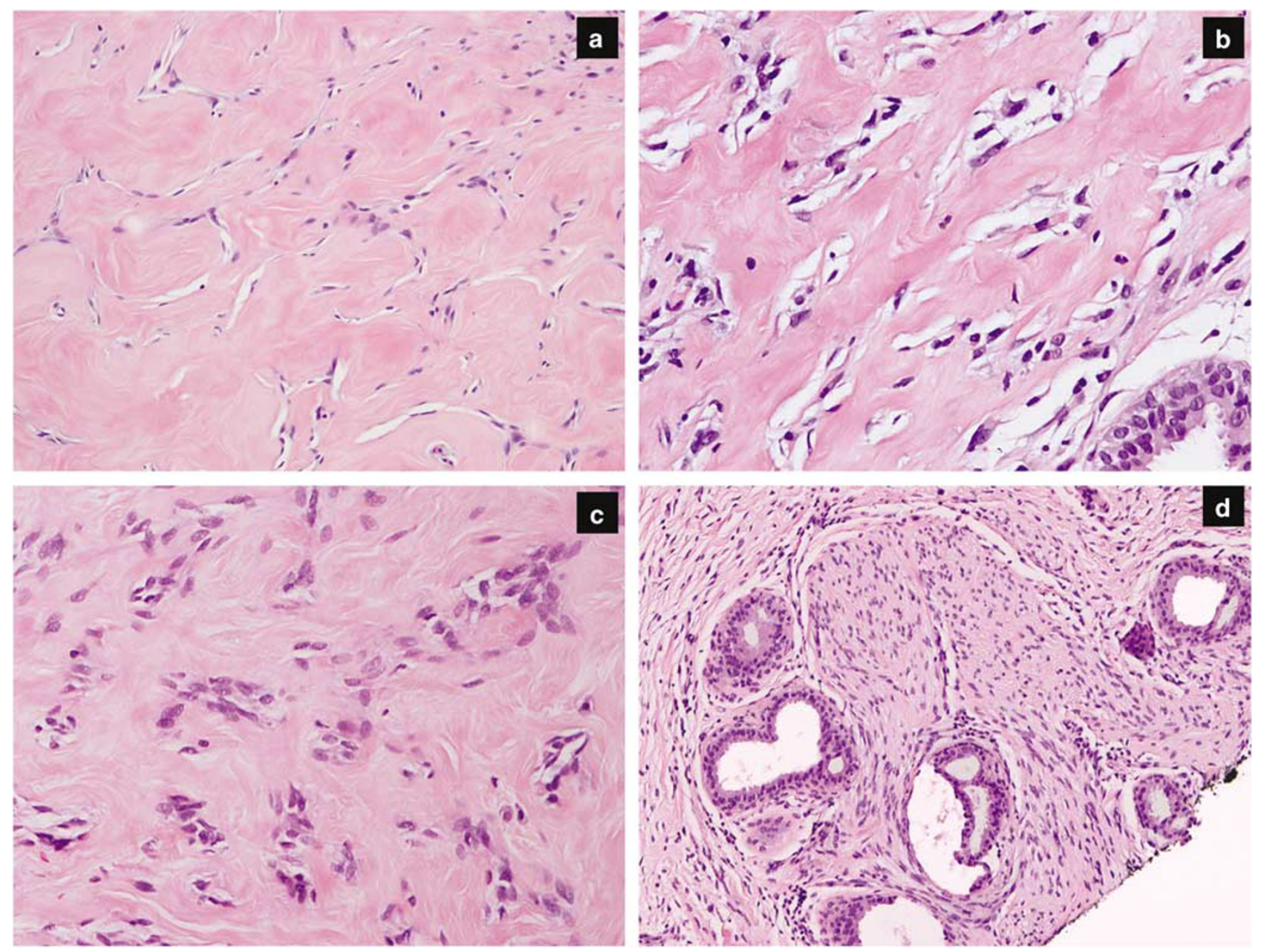

Figure 1 Histologic appearance of pseuadoangiomatous stromal hyperplasia. (a) Complex network of slender cords of myofibroblasts lining narrow inconspicuous empty spaces separated by collagenized stroma (hematoxylin and eosin stain, original magnification $\times$ 100). (b) Rare myofibroblasts that surround well-formed open empty spaces have enlarged, mildly hyperchromatic nuclei (hematoxylin and eosin stain, original magnification $\times 100)$. (c) Myofibroblastic hyperplasia in which myofibroblasts focally form small bundles (hematoxylin and eosin stain, original magnification $\times 100$ ). (d) In this fascicular variant, longitudinally sectioned intralobular bundles of myofibroblasts are noted in a background of conventional perilobular pseudoangiomatous stromal hyperplasia (hematoxylin and eosin stain, original magnification $\times 60$ ). 
appearance of example of pseudoangiomatous stromal hyperplasia tumors are depicted in Figures 1 and 2, and the histologic findings are summarized in Table 2.

The pseudoangiomatous stromal hyperplasia tumors were classified as simple in 18 cases $(69 \%)$ and fascicular/proliferative in eight cases (31\%). No cytologic atypia was found in stromal cells. In five of the 17 patients (29\%) with gynecomastia-like changes, the changes had originally been reported as columnar cell changes. There was a statistically significant association between the pseudoangiomatous stromal hyperplasia location in the intralobular stroma and the presence of gynecomastia-like changes $(P=0.00085)$.

\section{Case Report of Invasive Carcinoma within Pseudoangiomatous Stromal Hyperplasia Tumor}

In one patient, the sonography revealed a solid asymmetric density measuring $4.0 \mathrm{~cm}$. in greatest dimension with a $1.4 \mathrm{~cm}$ hypoechoic area within this lesion that was suspicious for malignancy on imaging. Core needle biopsy specimen of suspicious hypoechoic irregular area revealed invasive ductal carcinoma, however no obvious changes of pseudoangiomatous stromal hyperplasia were noted (Figure 3, inset). Only upon examination of the entire lesion on excisional specimen, it became obvious that invasive carcinoma $(0.9 \mathrm{~cm}$ in greatest dimension) was entirely confined to and occupied approximately up to one-third of the underlying pseudoangiomatous stromal hyperplasia tumor that was grossly well demarcated and measured $4.0 \mathrm{~cm}$ in greatest dimension (Figure 3).

\section{Follow-up Data}

Clinical or radiologic follow-up data were available for 15 patients (mean follow-up duration \pm s.d., $27 \pm 17$ months) (Table 3). One patient who had been diagnosed by core needle biopsy later
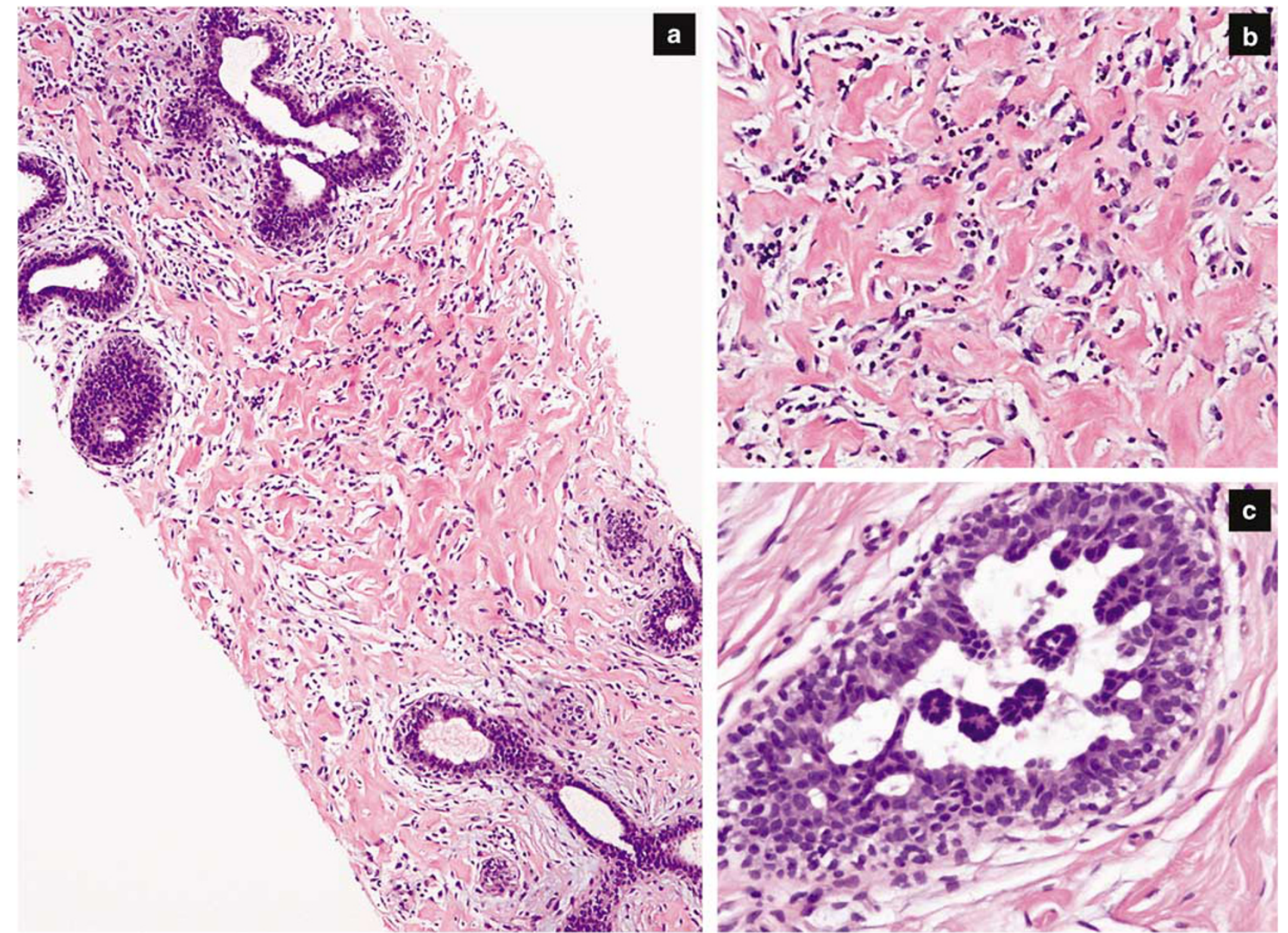

Figure 2 (a) Pseudoangiomatous stromal hyperplasia tumor on core needle biopsy with intralobular and perilobular stromal involvement by pseudoangiomatous stromal hyperplasia, gynecomastia-like changes and aborted lobule formation (hematoxylin and eosin stain, original magnification $\times 40$ ). (b) A higher magnification of pseudoangiomatous stromal hyperplasia with complex network of anastomosing and focally dilated spaces lined by myofibroblasts (hematoxylin and eosin stain, original magnification $\times 200$ ). $(\mathbf{c}) \mathrm{A}$ magnified view of duct with gynecomastia-like changes, micropapillary type, showing focal areas of peripheral fenestration. Both epithelial and myoepithelial cell proliferation contribute to hyperplasia (hematoxylin and eosin stain, original magnification $\times 200$ ). 
Table 2 Histologic findings

\begin{tabular}{lc}
\hline Histologic finding & No. of patients (\%) \\
\hline $\begin{array}{l}\text { Pseudoangiomatous stromal hyperplasia type } \\
\quad \text { Simple }\end{array}$ & $18(69)$ \\
Fascicular/proliferative & $8(31)$ \\
Cytologic atypia & 0 \\
Pseudoangiomatous stromal hyperplasia location & \\
$\quad$ Perilobular stroma & $5(19)$ \\
Intralobular stroma & 0 \\
Perilobular and intralobular stroma & $21(81)$ \\
Associated pathologic findings & \\
Benign breast lesions & \\
Gynecomastia-like changes & $8(31)$ \\
Gynecomastia-like changes and other benign & $9(35)$ \\
lesions & $8(31)$ \\
Invasive ductal carcinoma & $1(4)$ \\
\hline
\end{tabular}

${ }^{\mathrm{a}}$ Includes ductal hyperplasia without atypia, adenosis, apocrine metaplasia, cystic changes, and fibroadenomatoid changes.

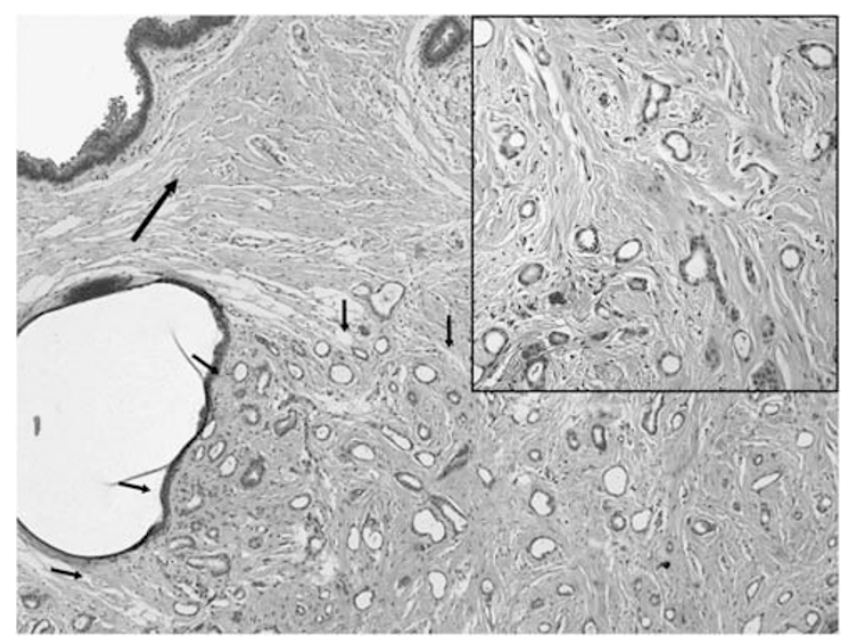

Figure 3 Invasive ductal carcinoma (short arrows) partially involves pseudoangiomatous stromal hyperplasia tumor (long arrow) (hematoxylin and eosin stain, original magnification $\times 40$ ). Pseudoangiomatous stromal hyperplasia changes in stroma of invasive tumor on core needle biopsy specimen were not so conspicuous (inset), and final diagnosis of underlying pseudoangiomatous stromal hyperplasia tumor was made only upon excision (hematoxylin and eosin stain, original magnification $\times 100)$.

underwent excision because the lesion had grown from 3.5 to $4.8 \mathrm{~cm}$ at its largest dimension in 27 months. Upon excision, pseudoangiomatous stromal hyperplasia tumor was evident but no additional pathology was found in this patient. No clinical or radiologic evidence of a recurrence of pseudoangiomatous stromal hyperplasia tumor or carcinoma was found in the patient with carcinoma within pseudoangiomatous stromal hyperplasia tumor after a follow-up period of 39 months. One patient with concomitant carcinoma diagnosed $2.0 \mathrm{~cm}$ apart of pseudoangiomatous stromal hyperplasia tumor is presently undergoing neo-adjuvant chemotherapy and have not yet underwent surgical excision. No interval changes within area corresponding to pseudoangiomatous stromal hyperplasia tumor by imaging were noted during therapy. In remaining patients with core needle biopsy and no excision, the pseudoangiomatous stromal hyperplasia tumor remained clinically and radiologically stable.

\section{Discussion}

In our series, a higher proportion of pseudoangiomatous stromal hyperplasia tumors was diagnosed in premenopausal women (62\%) than in postmenopausal women and was associated with hormone therapy use. The stromal cells in pseudoangiomatous stromal hyperplasia lesions have been found to be progesterone receptor positive,${ }^{11}$ and similarities have been found between pseudoangiomatous stromal hyperplasia and features of intralobular stroma during the luteal phase of the menstrual cycle; ${ }^{12}$ these findings support the hypothesis that pseudoangiomatous stromal hyperplasia is a hormone-related proliferation of intralobular stromal cells. ${ }^{1-3,6,11}$ We did not evaluate hormone receptors in pseudoangiomatous stromal hyperplasia tumors in our series, except one instance of pseudoangiomatous stromal hyperplasia tumor with concomitant invasive carcinoma, where we noticed a strong positivity of stromal cells of pseudoangiomatous stromal hyperplasia for progesterone receptor.

Most pseudoangiomatous stromal hyperplasia tumors mimic fibroadenomas or hamartomas on imaging and they are often described as welldefined masses on mammography ${ }^{8-10}$ and wellcircumscribed hypoechoic lesions on sonography. ${ }^{7-10}$ Most tumors in our study had been identified as hypoechoic lesions on sonography $(70 \%)$. Contrary to the findings of other published reports, indistinct margins were visible on mammography or sonography in $56 \%$ of our cases. However, most lesions in our study were still categorized as benign based on combined clinical impression and radiologic findings. In three patients, malignancy was suspected on imaging, mainly because of the irregular margin and the ill-defined or spiculated nature of the lesion, leading to recommendation for surgical excision. Radiologists and clinicians should be aware that no distinct radiologic characteristics have been found for pseudoangiomatous stromal hyperplasia tumors. In rare cases, pseudoangiomatous stromal hyperplasia could be radiologically indistinguishable from carcinoma and may be classified as indeterminate or suspicious for malignancy on imaging, typically leading to excision despite benign morphologic characteristics on core needle biopsy. A similar observation was reported in another pseudoangiomatous stromal hyperplasia case. ${ }^{8}$ To our knowledge, we first report the occurrence of invasive carcinoma arising in a background of pseudoangiomatous stromal hyperplasia tumor. 
Table 3 Diagnostic and therapeutic procedures and follow-up data

\begin{tabular}{|c|c|c|c|c|c|}
\hline Diagnostic procedure & $\begin{array}{c}\text { No. of } \\
\text { patients }\end{array}$ & $\begin{array}{l}\text { Pathologic } \\
\text { findings }\end{array}$ & $\begin{array}{l}\text { No. of patients } \\
\text { followed up (\%) }\end{array}$ & $\begin{array}{l}\text { Median length of } \\
\text { follow-up, months }\end{array}$ & Radiologic findings \\
\hline $\begin{array}{l}\text { Incisional or } \\
\text { excisional biopsy }\end{array}$ & 5 & $\begin{array}{l}\text { Pseudoangiomatous } \\
\text { stromal hyperplasia } \\
\text { tumor }^{\mathrm{a}}\end{array}$ & $4(80)$ & 35.5 & No additional lesions \\
\hline $\begin{array}{l}\text { Core needle biopsy } \\
\text { and surgical excision }\end{array}$ & 5 & $\begin{array}{l}\text { Pseudoangiomatous } \\
\text { stromal hyperplasia } \\
\text { tumor }^{\mathrm{b}}\end{array}$ & $3(60)$ & 16 & No additional lesions \\
\hline $\begin{array}{l}\text { Core needle biopsy } \\
\text { and no excision }\end{array}$ & 16 & NA & $8(50)$ & 27.5 & No change \\
\hline
\end{tabular}

${ }^{\mathrm{a}}$ In one patient, the pseudoangiomatous stromal hyperplasia tumor was partially involved by an invasive ductal carcinoma; no atypia or malignancy was found in the other four patients.

${ }^{\mathrm{b}}$ One patient underwent surgical excision after 27 months of follow-up because of increasing lesion size. The remaining four patients underwent excision immediately after core needle biopsy because of suspicious radiologic or clinical findings. No additional pathology was demonstrated on excision.

In our study, gynecomastia-like changes were strongly associated with pseudoangiomatous stromal hyperplasia tumors. Gynecomastia-like changes have been reported to be rare in women, ${ }^{13,14}$ and to our knowledge, they have not been reported in pseudoangiomatous stromal hyperplasia tumors, mainly because no other studies have focused on describing epithelial changes in the terminal ductal-lobular units of pseudoangiomatous stromal hyperplasia tumors. Pseudoangiomatous stromal hyperplasia changes have been reported in association with gynecomastia in men (23.8 and $47.4 \%$ of cases). ${ }^{5,15}$ Therefore, we were not surprised to find this association in women. The statistically significant association between intralobular pseudoangiomatous stromal hyperplasia and the presence of gynecomastia-like changes suggest that intralobular stromal cells could impair normal ductal-lobular unit development, probably by restricting perilobular space by pseudoangiomatous stromal hyperplasia proliferation. Hyperplastic changes in the epithelial and myoepithelial cells of terminal ducts in gynecomastia-like changes are sometimes prominent, and hyperplasia could mimic columnar cell changes. ${ }^{16}$ In our study, in five of the 17 patients with gynecomastia-like changes, the changes were originally misdiagnosed as columnar cell changes. Hyperplasia in gynecomastia-like changes could show prominent nuclear overlapping, nuclear hyperchromasia, and nucleoli and infrequent mitoses, and could be incorrectly classified as 'flat epithelial atypia'. However, in gynecomastia-like changes, the myoepithelial cells are hyperplastic; while in columnar cell changes these are typically normal appearing or flat. The incorrect diagnosis of gynecomastia-like changes as 'flat epithelial atypia' could lead to unnecessary surgery: the presently accepted treatment for 'flat epithelial atypia' is excision of the entire lesion because these lesions are associated with more advanced tumor types in approximately one-third of cases. ${ }^{15}$

To our knowledge, we report the first case of invasive ductal carcinoma localized in a pseudoan- giomatous stromal hyperplasia tumor. An asymmetric dense mass was visible that was suspicious for malignancy, and the subsequent core needle biopsy confirmed the diagnosis. This case may represent an incidental association of a common neoplasm with a rare breast lesion, similar to cases of carcinoma occurring in more frequent fibroadenomas.

Recently, Pruthi et $a 1^{17}$ reported the successful treatment of a patient with extensive bilateral pseudoangiomatous stromal hyperplasia tumors with tamoxifen, but further studies are needed to substantiate this as a treatment option. Reported rates of recurrence after excision have been highly variable, ranging from 0 to $28.5 \% .^{7,9}$ Rates of lesion growth, as demonstrated by consecutive imaging, have been reported to be $0-71.4 \% .^{1,9}$ In one patient in our study, the lesion grew during the 27-month follow-up period, prompting a subsequent surgical resection. No disease recurrence was reported in the 10 patients who had undergone initial surgical excision. Moreover, no further changes were found in the original lesions in patients who had undergone core needle biopsy but not excision. This observation indicates that pseudoangiomatous stromal hyperplasia tumors could be clinically or radiologically monitored instead of surgically excised in selected cases. If changes in the tumor are found on subsequent imaging studies, re-biopsy or surgical excision is an option. ${ }^{8}$ Surgical excision is indicated for tumors with a suspicious radiologic or clinical appearance, as occurred in four of our cases, to rule out underlying malignancy. The occurrence of an invasive ductal carcinoma in one case of pseudoangiomatous stromal hyperplasia tumor, although probably incidental, highlights the fact that the management of patients with pseudoangiomatous stromal hyperplasia tumors requires careful clinical and radiologic correlation and frequent discussion among the radiologist who performs the biopsy, the pathologist, and the clinician. ${ }^{8}$

In summary, a higher proportion of pseudoangiomatous stromal hyperplasia tumors was diagnosed 
in premenopausal women than in postmenopausal women and most cases were associated with hormonal therapy use. Gynecomastia-like changes were frequently found in pseudoangiomatous stromal hyperplasia tumors, and the presence of these changes was strongly associated with intralobular pseudoangiomatous stromal hyperplasia. All but one of the core needle biopsy-diagnosed pseudoangiomatous stromal hyperplasia tumors that were not subsequently excised remained clinically and radiologically stable; thus, close clinical surveillance may be an alternative option to surgery in selected patients after a benign pathology and benign imaging studies.

\section{Acknowledgement}

Supported by the Development Fund received from the University of Texas M. D. Anderson Cancer Center of the corresponding author.

\section{References}

1 Vuitch MF, Rosen PP, Erlandson RA. Pseudoangiomatous hyperplasia of mammary stroma. Hum Pathol 1986;17:185-191.

2 Ibrahim RE, Sciotto CG, Weidner N. Pseudoangiomatous hyperplasia of mammary stroma. Cancer 1989;63: 1154-1160.

3 Rosen PP. Pseudoangiomatous hyperplasia of mammary stroma. In: Rosen PP (ed). Rosen's Breast Pathology, 2nd edn. Lippincott Williams \& Wilkins: Philadelphia, PA, 2001, pp 757-766.

4 Milanezi M, Saggioro F, Zanati S, et al. Pseudoangiomatous hyperplasia of mammary stroma associated with gynaecomastia. J Clin Pathol 1998;51:204-206.

5 Badve S, Sloane JP. Pseudoangiomatous hyperplasia of male breast. Histopathology 1995;26:463-466.
6 Powell CM, Cranor ML, Rosen PP. Pseudoangiomatous stromal hyperplasia (PASH). Am J Surg Pathol 1995;19:270-277.

7 Mercado CL, Naidrich SA, Hamele-Bena D, et al. Pseudoangiomatous stromal hyperplasia of the breast: sonographic features with histopathologic correlation. Breast J 2004;10:427-432.

8 Cohen MA, Morris EA, Rosen PP, et al. Pseudoangiomatous stromal hyperplasia: mammographic, sonographic, and clinical patterns. Radiology 1996;198: 117-120.

9 Polger MR, Denison CM, Lester S, et al. Pseudoangiomatous stromal hyperplasia: mammographic and sonographic appearance. Am J Roentgenol 1995;166: 349-352.

10 Salvadora R, Lirolab JL, Domínguez R, et al. Pseudoangiomatous stromal hyperplasia presenting as a breast mass: imaging findings in three patients. The Breast 2004;13:431-435.

11 Anderson C, Ricci Jr A, Pedersen CA, et al. Immunocytochemical analysis of estrogen and progesterone receptors in benign stromal lesions of the breast. Evidence for hormonal etiology in pseudoangiomatous hyperplasia of mammary stroma. Am J Surg Pathol 1991;15:145-149.

12 Vogel PM, Georgiade NG, Fetter BF, et al. The correlation of histologic changes in the human breast with the menstrual cycle. Am J Pathol 1981;104:23-24.

13 Umlas J. Gynecomastia-like lesions in the female breast. Arch Pathol Lab Med 2000;124:844-847.

14 Kang Y, Wile M, Schinella R. Gynecomastia-like changes of the female breast. Arch Pathol Lab Med 2001;125:506-509.

15 Milanezi MF, Saggioro FP, Zanati SG, et al. Pseudoangiomatous hyperplasia of mammary stroma associated with gynaecomastia. J Clin Pathol 1998;51:204-206.

16 Schnitt SJ, Vincent-Salomon A. Columnar cell lesions of the breast. Adv Anat Pathol 2003;10:113-124.

17 Pruthi S, Reynolds C, Johnson RE, et al. Tamoxifen in the management of pseudoangiomatous stromal hyperplasia. Breast J 2001;7:434-439. 